\title{
POSIBILIDAD DE CONTROL INMUNOLOGICO DE VECTORES HEMATOFAGOS DE ENFERMEDADES HUMANAS
}

\author{
MIGUEL GUZMAN*, ALBERTO MORALES**, CARMEN ELISA ALARCON LOPEZ***, VICTOR ALBERTO OLANO***
}

\begin{abstract}
Se presenta un estudio preliminar para la inmunización con antígenos derivados del tuvo digestivo del Anopheles albimanus con la idea de obtener alteraciones celulares del tubo digestivo y de tal manera bloquear su infección con Plasmodium. El estudio demostró que es posible obtener anticuerpos contra componentes del tubo digestivo del mosquito y que el antígeno responsable no es homogéneo y único.
\end{abstract}

\section{INTRODUCCION}

Sabido es que dentro de la patología humana existe un grupo de entidades transmisibles: bacterianas, parasitarias y virales algunas de ellas de gran relevancia en salud pública, que son transmitidas por artrópodos hematófagos, y cuyo control es todavía problemático bien porque no existen vacunas o posibilidades de tratamiento efectivo y en donde el control del vector podría ser una estrategía decisiva para romper la cadena de transmisión. Ese control se a hecho fundamentalmente mediante plaguicidas, aunque también se ha intentado procedimientos biológicos tales como la toxina de Bacillus thuringiensis para Aedes aegypti (13), peces de los géneros Poecilia y Gambusia para mosquitos del género Anopheles y algunos nemátodos y Copepodos (4) entre otros.

En este orden de ideas hemos postulado la posibilidad de obtener un control de vectores hemoatófagos mediante efectos citotóxicos mediados por anticuerpos anti-vector desarrollados en el huésped.
El trabajo aquí presentado es un estudio preliminar sobre esta hipótesis.

\section{MATERIALES Y METODOS}

Artrópodos: para inmunizar los animales de experimentación: conejos, se seleccionó la especie Anopheles albimanus considerado como vector eficiete de Plasmodium en nuestro medio y mantenido en insectarios del Grupo de Entomología.

Conejos: se utilizaron conejos adultos tanto para la inoculación como para la alimentación de los mosquitos.

El aparato digestivo de mosquitos fue obtenido por disección y procesado cuando la masa alcanzó aproximadamente $1 \mathrm{mg}$. Los tubos digestivos fueron homogenizados en un disrruptor celular con solución salina buffer $\mathrm{pH} 7.2$ y el contenido de proteína, determinado por el método Lowry (5) este material fue utilizado para inocular conejos adultos de aproximadamente

\footnotetext{
* Jefe Grupo de Inmunología, Instituto Nacional de Salud. Profesor Asociado, Facultad de Medicina, Universidad Nacional de Colombia

**Jefe Grupo de Entolomogia, Instituto Nacional de Salud.

***Bióloga Unidad Inmunológica, Grupo Inmunología, Instituto Nacional de Salud.

****Biólogo Grupo de Entomologia, Instituto Nacional de Salud. Santafé de Bogotá, D.C. - Colombia.
} 
$1.500 \mathrm{~g}$ de peso. se inoculó por vía intracutánea múltiple $1 \mathrm{mg}$ de proteína en $1 \mathrm{ml}$ de adyuvante completo de Freund, un día específico cada semana durante 5 semanas, al término de los cuales se obtuvo una muestra por punción de la vena marginal de la oreja. Una vez separado el suero, éste se guardó a $4^{\circ} \mathrm{C}$ para pruebas posteriores de demostración de anticuerpos anticomponentes celulares del aparato digestivo del mosquito. Se realizaron pruebas de doble inmunodifusión, colocando en el pozo central una dilución del preparado celular y en la periferia diluciones dobles progresivas del antisuero, luego de la incubación a temperatura ambiente por 48 horas se observaron las placas para investigar la presencia de bandas de precipitación. Cuando el resultado fue positivo, se hizo pruebas de inmunoelectroforesis con el fin de establecer qué clase de inmunoglobulina reaccionaba con el antígeno del mosquito.

Una vez realizados estos estudios, se procedió a analizar el antígeno crudo con el objeto de diferenciar los componentes protéicos, mediante electroforesis en geles de Poliacrylamida. 25 microgramos de proteína fueron colocados en cada pozo de un gel: $\mathrm{T}=12.8 \%$,
$\mathrm{C}=4,5 \%$ y $\mathrm{T}=4.6 \%, \mathrm{c}=2.5 \%$. La metodología utilizada, fue una modificación de la Lemmli $(6,7)$. Marcadores de alto y bajo peso molecular fueron paralelamente corridos para ser estudiados en conjunto con las proteínas del homogenizado.

Una vez conocidos los aspectos anteriores se procedio a alimentar un grupo de Anapholes albimanuses en los conejos previamente inmunizados y observarlos por un período prudencial.

\section{RESULTADOS}

La inoculación de los conejos con material del tejido intestial de los mosquitos, resultó en formación de anticuerpos a la 5a semana a un título de 1:4 por técnica de doble inmunodifusión el cual no se incrementó con inoculaciones posteriores, una sola banda de precipitacin se observó en cada uno de los antisueros obtenidos de cada conejo, Fig. 1. Los estudios de inmunoeletroforesis mostraron que la banda de precipitación es causada por anticuerpos de tipo IgG fundamentalmente (Fig. 2).

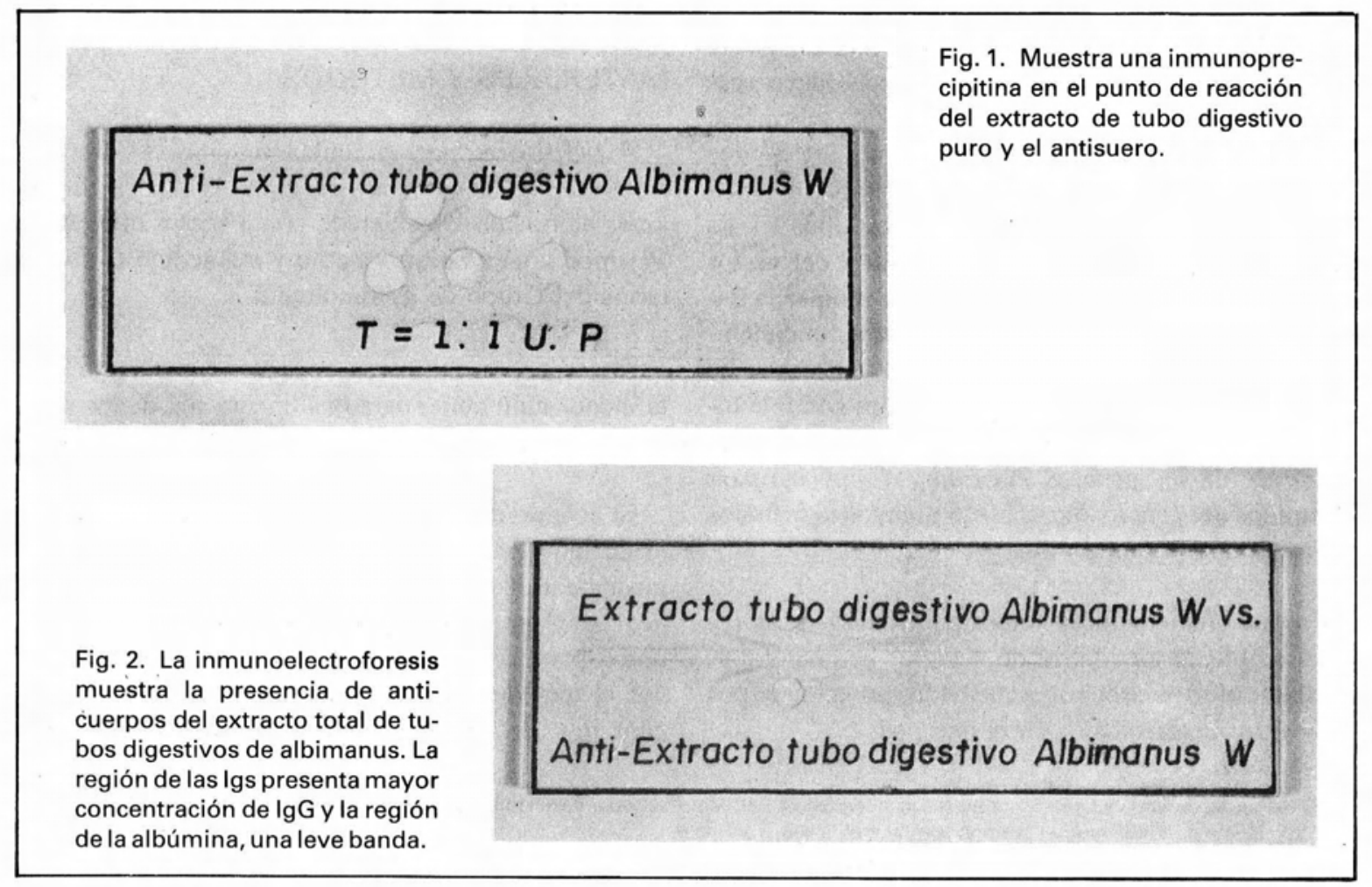




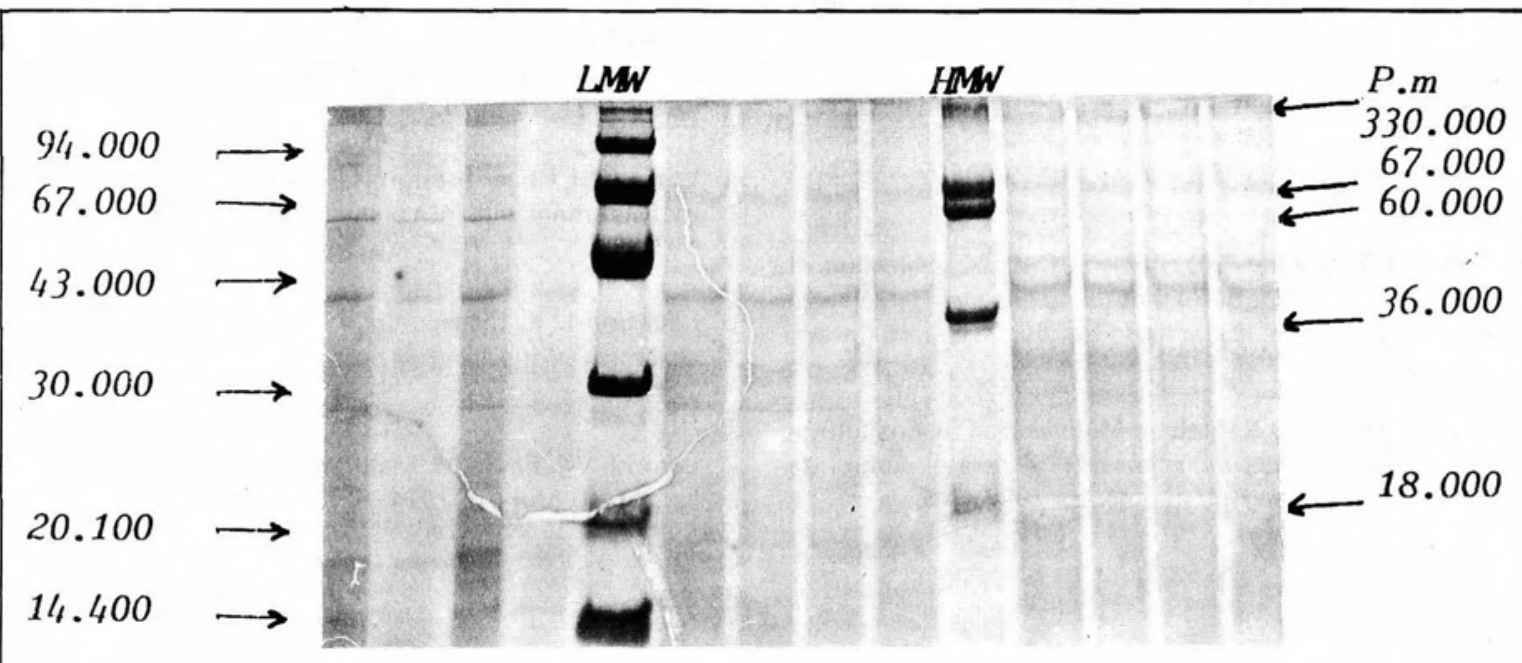

Fig. 3. El gel de Poliacrylamida muestra la complejidad del patrón electroforético de las proteínas, que conforman el antígeno y la aproximación de sus pesos moleculares frente a marcadores de alto y bajo peso.

El estudio de la composición de preparado crudo de tubo digestivo del mosquito mostró que este es complejo ya que se observa varias (6) bandas proteícas, cuyos pesos moleculares estan comprendidos entre 36.000 y $220.000 \mathrm{KD}$ (Fig. 3).

Los mosquitos alimentados con sangre de conejos inmunizados no mostraron cambios durante las primeras 48 horas de observación pero fueron extraídos sus tubos digestivos para posteriores estudios.

\section{DISCUSION}

Aunque el trabajo aquí expuesto no presenta aún resultados concluyentes, es conveniente presentarlo como paso inicial de un estudio completo que demuestre que realmente existen componentes del tubo digestivo del mosquito capaces de despertar una respuesta en términos de anticuerpos específicos; parece que el antígeno no es un componente único homogéneo según se desprende de los estudios realizados en gel de Poliacrylamida. Es lógico presumir que la hembra del mosquito al succionar la sangre y llenarse, reposa un tiempo prudencial; si los anticuerpos contenidos en la sangre interactúan con el complemento a la temperatura del mosquito, deben tener acción sobre los componentes antigénicos del tubo digestivo, lesionándo e inhabilitándolo para que el Plasmodium pueda cumplir su ciclo, posiblemente la acción de los anticuerpos no traiga como consecuencia la muerte del mosquito.
Es importante resaltar que aunque se trata de una proteína extraña no se despertó ningún tipo de hipersensibilidad en los conejos inoculados.

Los estudios posteriores que deban realizarse incluyen la localización del antígeno en las células digestivas mediante pruebas inmunoquímicas, la purificación y concentración del antígeno y la observación de daños tisulares en mosquitos alimentados permanentemente con los conejos inmunizados.

Cuando concluiamos esta fase del estudio, tuvimos conocimiento de los estudios realizados en Australia en el control de la garrapata del ganado (Amblyoma cayennensis) con un sistema similar al planteado por nosotros que se muestra altamente promisorio.

\section{SUMMARY}

A preliminary study is presented hereby on the possibility to immunize experimental animals with an antigen derived from cellular components of the digestive tract of Anopheles albimanus so that feeding of the mosquito could result in cellular damage of the digestive tract, blocking in some way the infection with Plasmodium. The studies realized so far, showed that a fraction from the digestive tract elicit antibody synthesis in rabbits and that these fraccions are not homogeneus. 
MIGUEL GUZMAN, ALBERTO MORALES, CARMEN ELISA ALARCON, VICTOR ALBERTO OLANO

\section{BIBLIOGRAFIA}

1. Golderg L, Margalit. Bacterial spore demostrating rapid lavicidad activity against Anapholes sergentii, Uranotaenia unguiculata, Aedes aegypti and Culex pipens. Mosq News 1977; 37: 355.

2. Perich MJ, Boobar LR, Stivers JC et al. evaluation of diverse formulations of Bacillus thurigiensis ver. Israelensis against Anopheles albimanus in Honduras. Israel J Entolo. 1989; 23: 45.

3. Suarez MF, Ayala D, Nelson M. Evalucion de dos formulaciones de Bacillus thurigiensis $\mathrm{H} 14$ para el control de larvas de Aedes aegypti. Biomédica 1987; 7:5.
4. Marten GG, Astaiza R, Suarez MF, et al. Natural control of larval Anopheles albimanus ( Diptera: Culicidae) by the predator Mesocyclops (Copepoda: Cyclopoida). J Med Entomol 1989; 26: 624.

5. Lowry $\mathrm{OH}$, Rosenbrough NJ, Lewis-Farr A, et al. Protein measurement with folin phenol reagent. J biol Cheun 1951; 193:265.

6. Laemmli U K. Cleavage of structural proteins during the assembly of the head of bacteriophage T4. Nature 1970; 227: 680 .

7. Lemmli VK, Favre M. Maturatio of the head of bacteriophage T4. J Mol biol 1974; 80: 575. 